\title{
Meta-analysis on the survival of short implants
}

\author{
Elsa Menchero-Cantalejo ${ }^{1}$, Cristina Barona-Dorado ${ }^{2}$, Miriam Cantero-Álvarez ${ }^{3}$, Fernando Fernández-Cáliz ${ }^{4}$, \\ José-Ma Martínez-González ${ }^{5}$
}

\author{
${ }^{1}$ Dentist. Master's degree in Oral and Dental Implant Surgery at the University Hospital of Madrid \\ ${ }^{2}$ Associate Professor of Oral Surgery. Complutense University of Madrid. Assistant Director of the Master's degree program in \\ Oral and Dental Implant Surgery at the University Hospital of Madrid \\ ${ }^{3}$ Professor of the Master's degree program in Oral and Dental Implant Surgery at the University Hospital of Madrid \\ ${ }^{4}$ Associate Professor at Complutense University of Madrid. Professor of the Master's degree program in Oral and Dental Implant \\ Surgery. University Hospital of Madrid \\ ${ }^{5}$ Professor of Maxillofacial Surgery. Complutense University of Madrid. Department Chief of Oral and Dental Implant Surgery \\ at the University Hospital of Madrid
}

Correspondence:

Department of Medicine and Oral Surgery, School of Dentistry, Complutense University of Madrid,

Plaza Ramón y Cajal, s/n. Madrid, Spain crisbarona@hotmail.com

Received: $02 / 03 / 2010$ Accepted: $11 / 10 / 2010$
Menchero-Cantalejo E, Barona-Dorado C, Cantero-Álvarez M, Fernández-Cáliz F, Martínez-González JM. Meta-analysis on the survival of short implants. Med Oral Patol Oral Cir Bucal. 2011 Jul 1;16 (4):e546-51. http://www.medicinaoral.com/medoralfree01/v16i4/medoralv16i4p546.pdf

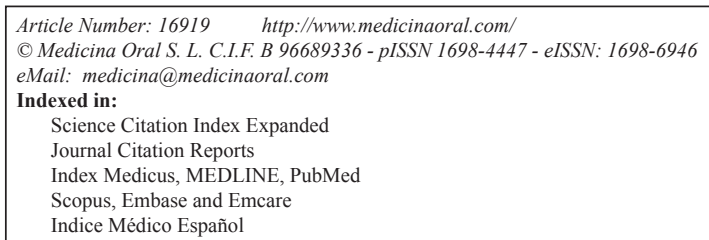

\begin{abstract}
Objective: To evaluate the success and failure rates of short implants $(10 \mathrm{~mm}$ or less) for oral rehabilitations in cases of limited bone height.

Study Design: Review of the articles published on the topic between the years 2000 and 2010, and development of a descriptive meta-analysis of the results.

Results: The majority of the studies obtain a cumulative success rate (CSR) similar to that of longer implants (92.5\% - 98.42\% for machined and rough-surface implants, respectively). The studies that record lower cumulative success rates (CSR) are later studies that analyze implants with a machined surface. Almost none of the studies compared the success/failure rates with the bone quality or location of the implant (maxilla or mandible). Thus, the results obtained are from a mixture of these parameters.

Conclusions: In view of the results analyzed, rehabilitations with short implants are a reliable treatment; however, the lack of consistency in the study designs as well as the presence of bias in all of the studies reviewed make it difficult to analyze the data.
\end{abstract}

Key words: Short dental implants, periodontitis, implant survival. 


\section{Introduction}

Severe atrophy of the maxilla makes it very difficult to use conventional removable prostheses. These move within the oral cavity, must be readjusted according to how the atrophy progresses, and do not permit certain forces for the trituration of food to be applied. In the case of younger patients with prolonged absences of one or more teeth or who suffer aggressive processes of periodontal disease, in the majority of the cases, it is not possible for a removable denture to be used due to the social stigma asssociated with them, as well as due to the aesthetic appearance that they give when the gaps extend up to the lateral sections, or even worse yet, when they affect the pre-maxilla area or the symphyseal area.

An atrophy of the maxilla results in an enlargement of the space for the prosthesis, and hence, a short implant has an unfavorable ratio in response to physical laws in terms of the application of levers, which is why atrophic maxillae have always been considered a risk factor when it comes to implant treatment (1-3). Other relevant factors that may affect the sucess rate of short implants are biomechanical factors.

An implant is considered to be short if it has a length that is equal to or less than $10 \mathrm{~mm}$. Years ago, these lengths were considered to be inadequate, especially in the maxilla, due to the qualitative characteristics of the bone at this level, which required a minimum availability of $13 \mathrm{~mm}$ from the alveolar ridge to the anatomical structures that outline the apical limit for the maxilla, and $10 \mathrm{~mm}$ in the case of the mandible. The development of new surface treatments and new implant designs appears to have made it possible to overcome these limitations, as is the case of rough-surface implants, which end up reducing the total length of the implant because there is more contact with the surface of the implant due to the roughness of its surface (3-21).

It is clear that the possibility of using short implants nowadays in order to achieve success rates similar to that of longer implants would be a great advantage, given that it would enable avoiding the prior preparation of the receiving area by means of more invasive surgical techniques.

\section{Material and Methods}

The articles referred to in the bibliography were collected through a search in PubMed using the keywords: short dental implants, periodontitis, implant survival. We selected articles on longitudinal studies that included short implants, considering these to be implants that measure $10 \mathrm{~mm}$ or less in length. The time parameters of the search were established between the years 2000 and 2010. The data was grouped into different tables according to the variables studied.

A meta-analysis of the results of the literature search was performed. The inclusion criteria were as follows: articles published between the years 2000 and 2010, studies with a follow-up of at least one year, studies on subjects of all ages. The exclusion criteria were: studies that focused on the periimplantary tissues, studies with non-physiological loads (orthodontics), studies carried out on laboratory animals and studies that, mentioning the use of short implants, do not clearly specify the measurements of the implants used.

The PubMed search resulted in 86 bibliographic entries, of which, according to the inclusion/exclusion criteria mentioned, 16 formed part of the meta-analysis as they were longitudinal studies (Table 1), and 5 were used as reference texts as they were bibliographic reviews or longitudinal studies that did not specifically include short implants, but did give out data on implants of longer lengths and could thus be used as a comparative reference. The articles selected fit within a wide range of study variables, the majority of which were not consistent with each other, thus making it difficult to perform a meta-analysis of the data. As it was not possible to obtain all the parameters defined in the descriptive statistics for each one of the articles, we have analyzed a sample that varies according to each parameter to be analyzed. These variables were as follows:

-Type of implant surface: machined or rough, the latter which may be due to subtraction or addition -Location of the implants: maxilla or mandible -Surgical protocol: one or two surgical stages

-Existence of habits: tobacco

-Success and failure rate: The success of the implant analyzed was defined as an implant that has completed its osseointegration and that has been able to be subjected to a functional load without observing the presence of any symptoms or evidence of the lack of osseointegration after being put into function.

\section{Results}

The total number of short implants analyzed in the studies was 7,392, and the total number of patients was unknown.

Of the implants, $37.97 \%$ (2807) were short implants with a machined surface, compared to $60.27 \%$ (4455) implants with a rough surface. Of the remaining short implants, that is $1.75 \%(129)$, the ratio of machined versus rough-surface implants was unknown. Thus, the most common type of surface was a rough surface.

Of the short implants, $46.28 \%$ were placed in two surgical stages, $11.49 \%$ (849) in one stage, $2.27 \%$ (168) in two stages+PRGF (platelet rich ground factors), 4.98\% (364) in one stage+PRGF, and $1.80 \%$ (133) of the implants were placed immediately after extraction. For $34.9 \%$ $(2,457)$ of the implants, the surgical procedure used was unknown. There were 2,872 (38.85\%) implants placed in different regions of the mandible, and 1,929 (26.10\%) 
Table 1. Results of the studies analyzed.

\begin{tabular}{|c|c|c|c|c|c|c|c|c|c|}
\hline & $\begin{array}{c}\text { Number } \\
\text { of } \\
\text { patients }\end{array}$ & $\begin{array}{l}\text { No. of short } \\
\text { implants/tot } \\
\text { al implants }\end{array}$ & \begin{tabular}{|c|} 
No. of short \\
impl./long impl. in \\
the maxilla or \\
low-density bone \\
(D3/D4) \\
\end{tabular} & $\begin{array}{l}\text { No. of short/long } \\
\text { implants in the } \\
\text { mandible } \\
\text { or high-density } \\
\text { bone (D1/D2) }\end{array}$ & Tobacco & Protocol & $\left|\begin{array}{c}\text { No. of short } \\
\text { rough } \\
\text { implants }\end{array}\right|$ & $\begin{array}{c}\text { No. of short, } \\
\text { machine- } \\
\text { surfaced } \\
\text { implants }\end{array}$ & $\begin{array}{l}\text { Cumulative } \\
\text { success rate }\end{array}$ \\
\hline $\begin{array}{l}\text { Bahat et al. (17) } \\
2000\end{array}$ & 202 & $313 / 660$ & $0 / ?$ & $313 / ?$ & Not specified & 2 stages & 0 & 313 & $\begin{array}{l}92.9 \% \text { in short } \\
\text { implants }\end{array}$ \\
\hline $\begin{array}{l}\text { Friberg et al. (1) } \\
2000\end{array}$ & 49 & $260 / 260$ & Not specified & Not specified & Not specified & 2 srages & 0 & 260 & $\begin{array}{l}93.9 \% \text { in short } \\
\text { implants }\end{array}$ \\
\hline $\begin{array}{l}\text { Davarpanah et al. } \\
\text { (19) } 2001\end{array}$ & 189 & $276 / 614$ & Not specified & Not specified & Not specified & 2 stages & 0 & 276 & $\begin{array}{l}92.9 \% \text { in short } \\
\text { implants }\end{array}$ \\
\hline $\begin{array}{l}\text { Testori et al. (11) } \\
2001\end{array}$ & 181 & $153 / 485$ & $102 / 266$ & $51 / 219$ & $\begin{array}{l}37 \text { patients (No. of } \\
\text { short implants } \\
\text { affected unknown) }\end{array}$ & Not specified & 153 & 0 & $\begin{array}{c}\text { Posterior maxilla: } \\
98.4 \% \text { of the total } \\
\text { implants } \\
\text { Posterior } \\
\text { mandible: } 99.4 \% \\
\text { of the total } \\
\text { implants } \\
\end{array}$ \\
\hline $\begin{array}{l}\text { Khang et al. (15) } \\
2001\end{array}$ & 97 & $129 / 432$ & $? / 225$ & $? / 207$ & $\begin{array}{l}19 \text { patients (No. of } \\
\text { short implants } \\
\text { affected unknown) }\end{array}$ & 2 stages & $?$ & $?$ & $\begin{array}{l}\text { Rough-surfaced: } \\
96.8 \% \text { in short } \\
\text { implants } \\
\text { Machine-surfaced: } \\
84.8 \% \text { in short } \\
\text { implants }\end{array}$ \\
\hline $\begin{array}{l}\text { Testori et al. (18) } \\
2002\end{array}$ & 175 & $158 / 405$ & $? / 123$ & $? / 282$ & $\begin{array}{c}19 \% \text { of patients who } \\
\text { smoke (No. of short } \\
\text { implants affected } \\
\text { unknown) }\end{array}$ & 1 stage & 158 & 0 & $\begin{array}{c}\text { Maxilla: } 98.4 \% \\
\text { Mandible: } 97.5 \%\end{array}$ \\
\hline $\begin{array}{l}\text { Naert et al. (14) } \\
2002\end{array}$ & 660 & $1,129 / 1,956$ & $? / 1,212$ & $? / 744$ & Not specified & 2 strages & 0 & 1,129 & $\begin{array}{l}67 \% \text { in short } \\
\text { implants }\end{array}$ \\
\hline $\begin{array}{l}\text { Weng et al. (12) } \\
2003\end{array}$ & 493 & $506 / 1,179$ & $? / 509$ & $? / 670$ & $\begin{array}{c}78 \text { patients (No. of } \\
\text { short implants } \\
\text { affected unknown) }\end{array}$ & 2 stages & 0 & 506 & $\begin{array}{l}89.0 \% \text { in short } \\
\text { implants }\end{array}$ \\
\hline $\begin{array}{l}\text { Tawill et al. (3) } \\
2003\end{array}$ & 111 & $269 / 269$ & 30 & 239 & Not specified & Not specified & 0 & 269 & $\begin{array}{l}95.5 \% \text { in short } \\
\text { implants }\end{array}$ \\
\hline $\begin{array}{l}\text { Romeo et al. (9) } \\
2006\end{array}$ & 129 & $265 / 265$ & 141 & 124 & No & Not specified & 265 & 0 & $\begin{array}{l}96.6 \% \text { in short } \\
\text { implants }\end{array}$ \\
\hline $\begin{array}{l}\text { Misch et al. (8) } \\
2006\end{array}$ & 273 & $745 / 745$ & $\begin{array}{l}523 \text { in bones } \mathrm{D} 3 \\
\text { and } \mathrm{D} 4\end{array}$ & 222 in bones D2 & Not specified & \begin{tabular}{|c|}
505 implants: \\
2 stages \\
240 imp.: 1 \\
stage \\
\end{tabular} & 745 & 0 & $\begin{array}{c}1 \text { phase: } 98.3 \% \text { in } \\
\text { short implants } \\
2 \text { phases: } 99.6 \% \\
\text { in short implants }\end{array}$ \\
\hline $\begin{array}{l}\text { Degidi et al. (5) } \\
2007\end{array}$ & $\begin{array}{c}\text { Not } \\
\text { specified }\end{array}$ & $133 / 133$ & Not specified & Not specified & $\begin{array}{l}\text { Yes (No. of patients } \\
\text { and short implants } \\
\text { affected unknown) } \\
\end{array}$ & $\begin{array}{c}\text { Immediate } \\
\text { post-extraction }\end{array}$ & 133 & 0 & $\begin{array}{l}97.7 \% \text { in short } \\
\text { implants }\end{array}$ \\
\hline $\begin{array}{l}\text { Anitua et al. (4) } \\
2008\end{array}$ & 293 & $532 / 532$ & 230 & 302 & Not specified & \begin{tabular}{|c|}
168 implants: \\
2 stages \\
(+PRGF) \\
364 implants: \\
1 stage \\
(+PRGF) \\
\end{tabular} & 532 & 0 & $\begin{array}{l}99.2 \% \text { in short } \\
\text { implants }\end{array}$ \\
\hline $\begin{array}{l}\text { Fugazzotto et al. } \\
\text { (7) } 2008\end{array}$ & 1,774 & $2,073 / 2,073$ & 807 & 1,266 & $\begin{array}{l}\text { Yes (No. of patients } \\
\text { and short implants } \\
\text { affected unknown) }\end{array}$ & Not specified & 2,073 & 0 & $\begin{array}{l}98.9 \% \text { in short } \\
\text { implants }\end{array}$ \\
\hline $\begin{array}{l}\text { Renouard et al. } \\
\text { (13) } 2006\end{array}$ & 85 & $96 / 96$ & 96 & 0 & Not specified & 1 stage & 42 & 54 & $\begin{array}{c}\text { Rough-surfaced: } \\
97.6 \% \text { in short } \\
\text { implants } \\
\text { Machine-surfaced: } \\
\text { 92.6\% in short } \\
\text { implants }\end{array}$ \\
\hline $\begin{array}{l}\text { Grant et al. (21) } \\
2009\end{array}$ & 124 & $355 / 255$ & 0 & $335 / 0$ & Not specified & 1 stage & 355 & 0 & $\begin{array}{l}99 \% \text { in short } \\
\text { implants }\end{array}$ \\
\hline
\end{tabular}

(*imp: implant; ${ }^{* *}$ pats.: patients; $* * *$ mandib.: mandible)

placed in the maxilla. Of the remaining $35.05 \%$ of the implants $(2,591)$, the specific location is unknown.

As far as the success rate is concerned, the range of results is defined by studies in which the success rates of implants with smooth and with rough surfaces were evaluated. In the studies that analyze machined-surface implants, the average CSR (cumulative success rate) obtained was $92.5 \%$. As for implants with a rough surface, the average was found to be $98.38 \%$. The average success rate is distributed as follows (Fig. 1) for implants 


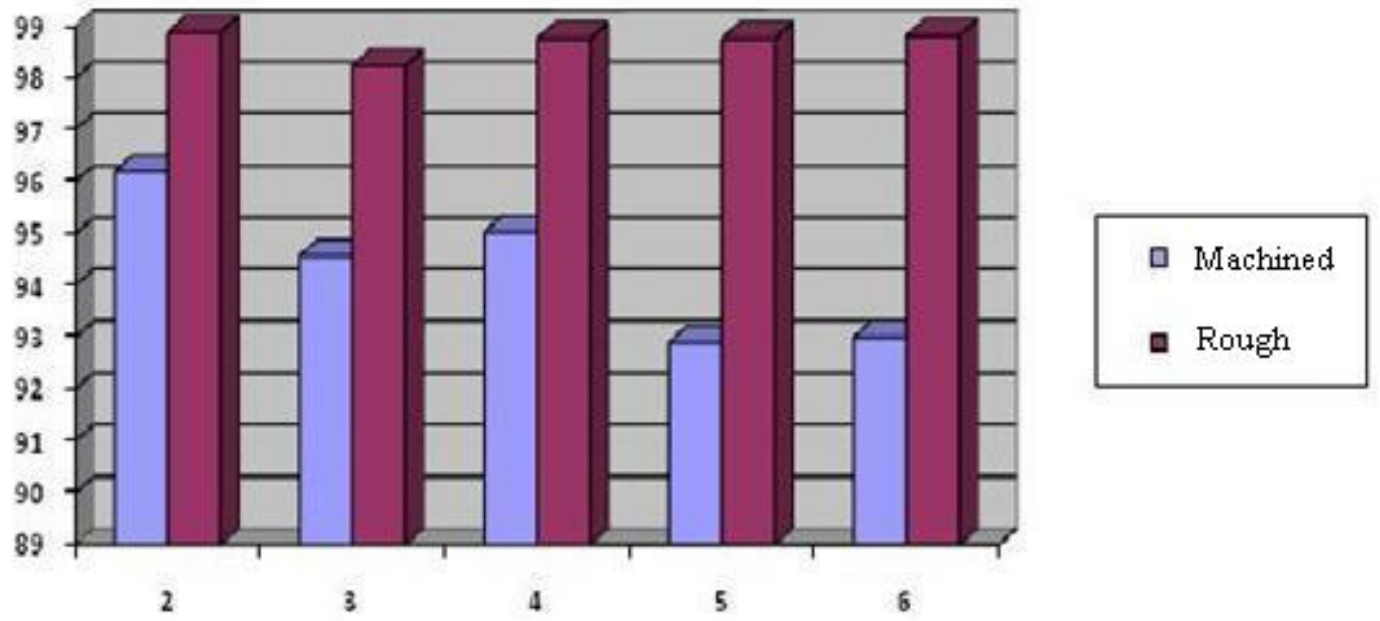

Fig. 1. CSR (cumulative success rate) of machine-surface implants compared to rough-surface implants, according to years of tracking the studies.

with a smooth surface and with a follow-up of up to 2 years, the average CSR is $96.2 \%$; for a 3-year follow-up, the CSR is $94.57 \%$; at 4 years, it is $95.03 \%$; for 5 years, it is $92.9 \%$; and for a 6 -year follow-up, it is $93.0 \%$. Naert et al. (14) manage to carry out a 16-year follow-up, and their CSR is $67.0 \%$. In the same manner, the results of the rough-surface implants are: for a one year followup, the CSR is $99.2 \%$; for 2 years, it is $98.88 \%$; for 3 years, it is $98.23 \%$; for 4 years, it is $98.76 \%$--a value that is maintained at the 5-year follow-up - and at 6 years, it is $98.82 \%$.

As for those patients who use tobacco, results were not obtained for this variable.

\section{Discussion}

We must keep in mind that in the majority of cases when we are considering the placement of short implants, the alternative of the choice of advanced surgical techniques in order to obtain a greater amount of bone comes into play. Therefore, the success rates of these techniques must be considered; hence, the longer implants placed in grafted areas (both with autologous bone as well as with allograft). That is not the objective of this present study, but in an effort to touch on this point, we will say that in making reference to the review by Del Fabbro (16), the success rate of the implants placed in the maxilla subjected to sinus lifts was $91.5 \%$. Thus, the data obtained in this study very much supports rehabilitation techniques in which short implants are used.

It is impossible to analyze this data without the individualization of the follow-up studies carried out in each case. The cumulative success rates vary substantially, if we analyze studies such as those by Bahat et al. (17), who perform a follow-up of 313 machined-surface implants for up to a maximum period of 5 years
(60 months), reaching a CSR of $92.9 \%$, compared to the data by Naert et al. (14), who carried out a 16-year follow-up (144 months) with a CSR of $67 \%$. In the case of the longitudinal studies of rough-surface implants, we found very similar CSR, ranging between $97.5 \%$ for Testori et al. (11) (36-month follow-up) and 97.5\% for Anitua et al. (4) and Grant et al. (21), with a 12-month and 24-month follow-up, respectively. In the review conducted by Domingues das Neves et al. (6), in which they analyzed various longitudinal studies with short rough-surface implants, the success rates that were obtained were similar to our own, with an average failure rate of $4.8 \%$ (CSR 95.2\%).

Based on our findings, we can see the stability of the rough-surface implants after a 6-year follow-up, as opposed to the downward trend with implants that have a smooth surface. We can assume that when having studies with longitudinal follow-ups with a longer time parameter, the trend of the graph would be maintained (Fig. 1), but none of the studies analyzed provided data for a period of more than 6 years. The machine-surface implants, however, follow this progressive decline according to how the follow-up period increases, passing from an initial approximate percentage of $96 \%$ on average for all of the 1-year follow-ups, to $92.9 \%$ at 6 years. It is common to observe how the majority of the studies consulted are limited to mentioning the percentage and/ or number of failures, without describing the characteristics of the implants lost. There is a clear difference in terms of the survival rates of the studies that analyze the success rate of implants inserted at times when implants with a smooth or machined surface were predominantly used. Studies such as those by Bahat et al. (17) or Naert et al. (14) show a higher rate of failures in short implants compared to longer implants, both in the pre-loading stages as well as in stages after the functional loading. 
The success rates with short implants continued to be acceptable rates, given that they managed to reach a cumulative value close to $92 \%$, even for 14 -year followups. With the appearance of implants with a rough surface and the publishing of results on this subject, we can see how the cumulative success rates increase to percentages similar to those found in studies on longer implants.

Other relevant factors that may affect the success or failure rate of dental implants have to do with biomechanical factors. Thus, implant-crown relationships that exceed the ratio 1:1 are harmful for any implant $(8,9)$. It is logical to think that a short implant falls into this category in many instances, which is why special care must be taken when developing the patient's occlusal pattern once reaching the prosthesis stage of rehabilitation, avoiding contact in lateral movements. As can be observed in this study, the introduction of rough surfaces has significantly improved the results in terms of long and short implant survival, the latter being the implants that have benefited the most from this surface treatment, given that by increasing the bone-implant contact surface, this largely offsets the existence of inadequate crown-implant ratios. The placement of a greater number of implants is also a good solution for offsetting an unfavorable crown-implant ratio, given that it considerably decreases the stress placed on the bone surrounding the implants.

The majority of the studies do not provide CSR data on the short implants studied with respect to the location of the implants. Only Testori et al. (11) offer such data, but with regard to the total implants included in their study, and not on short implants. Thus, the majority of the authors process the data described without considering the association between the success rate and the location of the implants. Testori et al. (11), Tawil et al. $(3,10)$ and Romeo et al. (9) make a distinction in their sample of implants analyzed, in which they indicate how many of the implants included in their study were inserted in the maxilla or in the mandible, although they do not clarify how many of them were placed in anterior, middle or posterior positions. The association of the location of the implants with the success/failure rate was not carried out by any of the authors mentioned.

Clearly, one of the most important factors to keep in mind when discussing the success rate of any implant is the bone quality of the implant bed. One of the areas that is most conducive to the placement of short implants, due to its anatomy in relationship with the maxillary sinus, is the posterior maxilla area, which by definition is the area with the poorest bone quality due to its low density. The majority of the authors consulted for this article associate the higher number of their failures to this situation, although, as we have mentioned previously, they do not provide specific data on the ex- act percentage of failures in which deficient bone quality is involved.

Of all of the studies analyzed, none of them take the factor of tobacco use into consideration when analyzing their results. Testori et al. (11), Khang et al. (15) and Weng et al. (12), indicate the number of patients included in their study who regularly use tobacco. Fugazzotto et al. (7) only declare that among the members of the sample, there are some who are smokers. Romeo et al. (9) indicate that patients who smoke were automatically excluded from their study. The rest of the articles did not define this factor. However, the studies that do indicate that there are a certain number of smokers among the subjects of the sample at the time of analyzing the results, do not provide any data that relates the success or failure rate of the implants with the fact that they were inserted in patients who use tobacco.

\section{References}

References with links to Crossref - DOI

1. Friberg B, Gröndahl K, Lekholm U, Brånemark PI. Long-term follow-up of severely atrophic edentulous mandibles reconstructed with short Brånemark implants. Clin Implant Dent Relat Res. 2000;2:184-9.

2. Goodacre CJ, Bernal G, Rungcharassaeng K, Kan JY. Clinical complications with implants and implant prostheses. J Prosthet Dent. 2003;90:121-32.

3. Tawil G, Aboujaoude N, Younan R. Influence of prosthetic parameters on the survival and complication rates of short implants. Int $\mathrm{J}$ Oral Maxillofac Implants. 2006;21:275-82.

4. Anitua E, Orive G, Aguirre JJ, Andía I. Five-year clinical evaluation of short dental implants placed in posterior areas: a retrospective study. J Periodontol. 2008;79:42-8.

5. Degidi M, Piattelli A, Iezzi G, Carinci F. Immediately loaded short implants: analysis of a case series of 133 implants. Quintessence Int. 2007;38:193-201

6. Das Neves FD, Fones D, Bernardes SR, Do Prado CJ, Neto AJ. Short implants-an analysis of longitudinal studies. Int J Oral Maxillofac Implants. 2006;21:86-93.

7. Fugazzotto PA. Shorter implants in clinical practice: rationale and treatment results. Int J Oral Maxillofac Implants. 2008;23:487-96.

8. Misch CE, Steignga J, Barboza E, Misch-Dietsh F, Cianciola LJ, Kazor C. Short dental implants in posterior partial edentulism: a multicenter retrospective 6-year case series study. J Periodontol. 2006;77:1340-7.

9. Romeo E, Ghisolfi M, Rozza R, Chiapasco M, Lops D. Short (8-mm) dental implants in the rehabilitation of partial and complete edentulism: a 3- to 14-year longitudinal study. Int J Prosthodont. 2006;19:586-92.

10. Tawil G, Younan R. Clinical evaluation of short, machined-surface implants followed for 12 to 92 months. Int J Oral Maxillofac Implants. 2003;18:894-901.

11. Testori T, Wiseman L, Woolfe S, Porter SS. A prospective multicenter clinical study of the Osseotite implant: four-year interim report. Int J Oral Maxillofac Implants. 2001;16:193-200.

12. Weng D, Jacobson Z, Tarnow D, Hürzeler MB, Faehn O, Sanavi $\mathrm{F}$, et al. A prospective multicenter clinical trial of $3 \mathrm{i}$ machined-surface implants: results after 6 years of follow-up. Int J Oral Maxillofac Implants. 2003;18:417-23.

13. Renouard F, Nisand D. Impact of implant length and diameter on survival rates. Clin Oral Implants Res. 2006;17 Suppl 2:35-51.

14. Naert I, Koutsikakis G, Duyck J, Quirynen M, Jacobs R, Van Steenberghe D. Biologic outcome of implant-supported restorations in the treatment of partial edentulism. part I: a longitudinal clinical evaluation. Clin Oral Implants Res. 2002;13:381-9.

15. Khang W, Feldman S, Hawley CE, Gunsolley J. A multi-center 
study comparing dual acid-etched and machined-surfaced implants in various bone qualities. J Periodontol. 2001;72:1384-90.

16. Del Fabbro M, Testori T, Francetti L, Weinstein R. Systematic review of survival rates for implants placed in the grafted maxillary sinus. Int J Periodontics Restorative Dent. 2004;24:565-77.

17. Bahat $\mathrm{O}$. Brånemark system implants in the posterior maxilla: clinical study of 660 implants followed for 5 to 12 years. Int J Oral Maxillofac Implants. 2000;15:646-53.

18. Testori T, Del Fabbro M, Feldman S, Vincenzi G, Sullivan D, Rossi R Jr, et al. A multicenter prospective evaluation of 2-months loaded Osseotite implants placed in the posterior jaws: 3-year followup results. Clin Oral Implants Res. 2002;13:154-61.

19. Davarpanah M, Martinez H, Tecucianu JF, Alcoforado G, Etienne D, Celletti R. The self-tapping and ICE $3 \mathrm{i}$ implants: a prospective 3-year multicenter evaluation. Int J Oral Maxillofac Implants. 2001;16:52-60

20. Romeo E, Bivio A, Mosca D, Scanferla M, Ghisolfi M, Storelli $\mathrm{S}$. The use of short dental implants in clinical practice: literature review. Minerva Stomatol. 2010;59:23-31

21. Grant BT, Pancko FX, Kraut RA. Outcomes of placing short dental implants in the posterior mandible: a retrospective study of 124 cases. J Oral Maxillofac Surg. 2009;67:713-7. 